\title{
BRAND IMAGE, USABILITY APLIKASI DAN PROMOSI TERHADAP REORDER CUSTOMER GRAB DI KOTA SOLO
}

\author{
Wahid Ali Imron', Sudarwati², Istiqomah ${ }^{3}$ \\ Fakultas Ekonomi Universitas Islam Batik Surakarta \\ Email Korespodensi : wahidaliimron@gmail.com
}

\begin{abstract}
Reorder is the most important thing in corporate marketing, Reorder itself can be influenced by several things. This study aims to determine the simultaneous and partial influence of the variables Brand Image, Application Usability, and Promotion on Reorder on Grab Customer in Solo. In addition, it is also to determine whether there is a significant simultaneous influence and which variable is the most dominant in influencing Reorder on Grab Customer in Solo City. The method used is descriptive quantitative method. The population is all Grab customers in the city of Solo. The sample used was 100 people with purposive sampling method. The research data analysis method is multiple linear analysis. The result is that the independent variables simultaneously influence the dependent variable having a siginfikansi $0.000<0.05$. Partially, brand image has an effect on reorder of Grab customers in Solo, which has a siginfikansi of 0.008 $<0.05$. Usability application has a significance of $0.010<0.05$ to affect reorder. The promotion significance is $0.885>0.005$ so the reorder is not influenced by the promotion.
\end{abstract}

Keywords: Brand Image, Application Usability, Promotion and Reorder

\section{PENDAHULUAN}

Setiap para pelaku usaha ataupun Perusahaan tentunya memiliki cara dan setrategi tersendiri agar Bisnis mereka tetap berjalan dan mendapatkan laba, Persaingan yang sangat ketat tentunya menjadikan perusahaan untuk selalu mempelajari agar para konsumen tidak pindah ke perusahan.

Untuk meningkatkan keyakinan konsumen untuk Reorder kembali terhadap Produk atau Jasa yang perusahaan hasilkan maka perusahaan harus mempertimbangkan beberapa faktor salah satunya adalah Brand Image. Sebuah merek jika sudah terkenal, sudah bagus, sudah terpercaya maka akan semakin mudah untuk membuat konsumen itu untuk melakukan pembelian, seiring berjalannya waktu maka konsumen akan terus membeli produk-produk dari merek perusahaan yang ia percayai dari segi kualitas dan yang lainnya yang kemudian akan memnimbulkan sebuah perasaan untuk membeli ulang.

Selain itu ada juga faktor yang mempengaruhi Reorder yaitu Kemudahan atau Usability, (Trisnawati, Suroso, Kumrorohadi : 2012). Semakain mudah, semudah simpel sebuah aplikasi untuk dapat dipahami serta dimengerti oleh konsumen maka akan semakin mengurangi beban dari konsumen itu sendiri. Aplikasi yang mudah dimengerti dan dipahami akan menghemat waktu juga.

Selanjutnya faktor yang mempengaruhi reorder adalah Promosi. Promosi merupakan variabel yang berpengaruh paling kecil terhadap keputusan pembelian ulang, Promosi pastinta akan benar-benar di fikirkan dan oleh perusahaan untuk menunjang Konsumen melakukan Reorder. 
Dari Uraian di atas penulis layak melakukan penelitian dengan judul Brand image, Usability aplikasi, dan Promosi terhadap Reorder pada Customer Grab di Kota Solo

\section{TINJAUAN PUSTAKA}

\section{Reorder}

Loyalitas konsumen ataupun juga sering dikatakan sebagai perilaku pembelian ulang oleh konsumen, perilaku ini biasanya dilakukan oleh konsumen kepada suatu produk yang sudah ia percayai karena merknya, harganya, ataupun hal-hal yang lain. Jika seorang konsumen sudah loyal kepada suatu merek atau perusahaan maka apapun yang ia ingin beli maka akan tertuju pada merek yang telah ia percayai. Berikut segala sesuatu yang dapat meningkatkan loyalits konsumen antara lain (1) Menghubungi konsumen secara berkala (2) Menbuat atau menciptakan produk ataupun jasa yang berkualitas bagus (3) Membalas keluh kesah konsumen dengan tanggap (4) Menerima masukan dari konsumen (5) Produk yang dijual harus jelas dan transparan (Tjiptono, 2014:392).

\section{Brand Image}

Citra merek atau dalam bahasa kerennya adalah brand image merupakan sebuah aset yang sangat berharga yang harus dipertahankan oleh perusahaan jika sudah mempunyai citra yang baik. Dikarenakan citra yang baik akan selalu memudahkan konsumen untuk dapat loyal kepada perusahaan ataupun merek.

Sebaliknya citra merek yang buruk justru akan membuat perusahaan akan mengalami kesusahan dalam memasarkan produknya. Untuk bisa sebuah merek agar dapat lebih dikenal lagi oleh publik adalah (1) Pelanggan harus diidentifikasi terlebih dulu (2) Harus mengetahui tujuan dari sebuah bisnis yang ingin dijalankan (3) Membuat sebuah merek menjadi berbeda dari yang lainnya (4) Mengembangkan pesan-pesan dari sebuah pemasaran (Kotler and Keller 2009:403).

\section{Usability Aplikasi}

Davis (1989) mendefinisikan persepsi kemudahan penggunaan. Semakain mudah, semudah simpel sebuah aplikasi untuk dapat dipahami serta dimengerti oleh konsumen maka akan semakin mengurangi beban dari konsumen itu sendiri. Aplikasi yang mudah dimengerti dan dipahami maka akan sangat mudah untuk dapat digunakan oleh konsumen sehingga dapat menghemat waktu juga. Dengan demikian manfaat lain yang didapat dari fakor kemudahan dalam menggunakan aplikasi akan membuat konsumen menjadi lebih nyaman dan kemudia akan menimbulkan minat untuk melakukan order ulang.

\section{Promosi}

Menurut Tjiptono (Nugroho, 2010) mengungkapkan bahwa promosi merupakan segala sesuatu yang dilakukan oleh perusahaan yang akan menjual atau memasarkan prosuknya, persuhaan akan selalu memulai menjual prosuknya dengan cara promosi yaitu dengan cara yang pertama mengingatkan bahwa mereka telah mengeluarkan produk terbaru dan berharap diterima oleh konsumen. Promosi yang menarik akan membuat produk semakin cepat dikenal karena promosi yang menarik akan membuat konsumen tertarik juga dan semakin mencari tau tentang produk yang dipromosikan. 


\section{Kerangka Pemikiran}

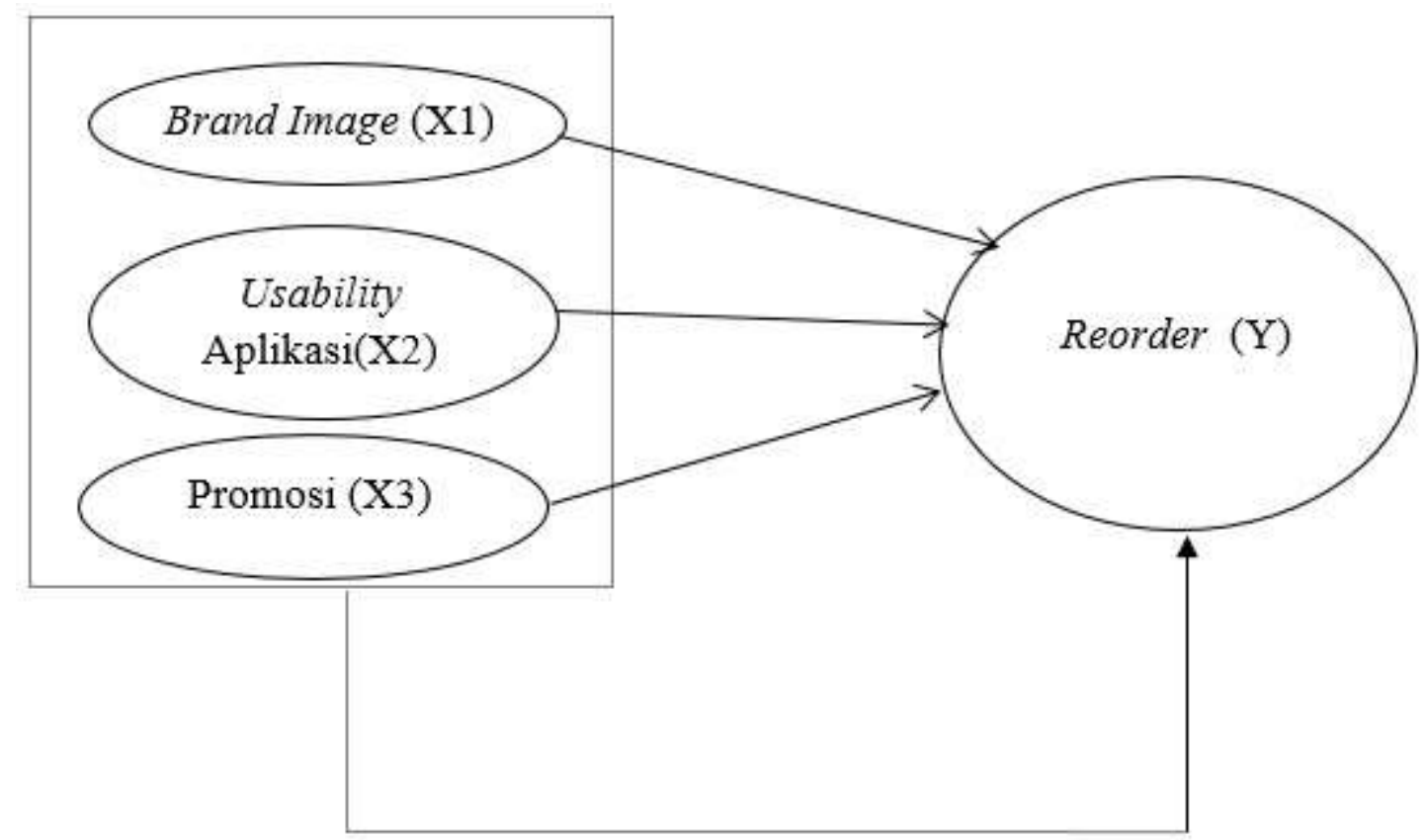

\section{Hipotesis}

H1 : Pengaruh brand image terhadap reorder customer Grab di Kota Solo

H2 : Pengaruh usability aplikasi terhadap reorder customer Grab di Kota Solo

H3 : Pengaruh promosi terhadap reorder customer Grab di Kota Solo

\section{METODOLOGI}

Jenis penelitian ini yaitu kuantitatif, data peneliti yaitu primer didapat dengan cara menyebar kuesioner serta analisis regresi linier berganda menjadi metode dipilih peneliti. Sedangkan metode pengumpulan data menggunakan purposive sampling. Polulasi pada penelitian ini yaitu semua customer Grab di Kota Solo.

\section{HASIL DAN PEMBAHASAN}

\section{Uji Asumsi Klasik}

Hasil uji normalitas penelitian ini menunjukkan bahwa data terdistribusi normal dengan nilai signifikansi sebesar 0,637 . Hasil uji multikolinieritas menghasilkan brand image memiliki nilai tolerance $0,405>0,10$ dan nilai VIF 2,470<10. Usability Aplikasi memiliki nilai tolerance $0,949>0,10$ dan nlai $V I F$

$1,054<0,10$. Dan promosi memiliki nilai tolerance $0,414>0,10$ dan nilai VIF $2,414<0,10$ sehingga dapat disimpulkan semua variabel independen tidak terjadi multikolinieritas. Hasil uji heteroskedastisitas menunjukka bahwa brand image memiliki nilai signifikansi 0,405, Usability aplikasi dengan nilan signifikansi 0,949 dan nilai signifansi promosi 0,414 sehingga dapat disimpulkan semua variabel independen tidak terjadi heteroskedastisitas. 


\section{Analisis Linier Berganda}

Tabel 1.1 Hasil Uji Analisis Linier Berganda

\begin{tabular}{lc}
\hline Variabel & B \\
\hline (Constant) & 10,837 \\
Brand Image & 0,290 \\
Usability Aplikasi & 0,208 \\
Promosi & $-0,200$ \\
\hline
\end{tabular}

\section{Sumber: Data diolah peneliti, 2020}

Dari tabel 1.1 uji regresi linier berganda diperoleh persamaan model regresi sebagai berikut $: \mathrm{Y}=10,837+0,290+0,208-200+\mathrm{e}$

Kelayakan Model

Tabel 1.2 Hasil Uji F

\begin{tabular}{|c|c|c|c|c|c|}
\hline Model & Fhitung & Ftabel & Sig. & Kriteria & Keterangan \\
\hline $\begin{array}{l}\text { Regressi on } \\
\text { Residual }\end{array}$ & 9,604 & 2,7 & 0,000 & $<0,05$ & Ditolak \\
\hline
\end{tabular}

Dari tabel 1.2 diperoleh F hitung > F tabel $(9,604>2,7)$ dengan nilai signifikansi sebesar 0,000 dan dapat disimpulkan bawha variabel brand image, usability aplikasi dan promosi secara bersamaan berpengaruh terhadap reorder customer Grab di Kota Solo. Hasil uji determinasi menunjukka nilai ajusted $\mathrm{R}$ square sebesar 0,520 .

Tabel 1.3 Hasil Uji t

\begin{tabular}{lccccl}
\hline Variabel & thitung & Ttabel & Sig. & Kriteria & Keterangan \\
\hline Brand Image & 2,693 & 1,984 & 0,000 & $<0,05$ & Diterima \\
Usability & aplikasi 1,984 & 0,010 & $<0,05$ & Diterima \\
2,639 & -145 & 1,984 & 0,885 & $<0,05$ & Ditolak \\
Promosi & & & & & \\
\hline
\end{tabular}

Sumber: Data diolah peneliti, 2020

\section{PEMBAHASAN}

\section{Hasil Hipotesis 1}

Diketahui brand image mempunyai t hitung 2,693 dan t tabel 1,984 maka $(2,693>1984)$ serta signifikansi 0,000<0,05. Disimpulkan bahwa reorder customer Grab di Kota Solo dipengaruhi oleh brand image. Penelitian ini selaras dengan (Efendy, Widyaningrum dan Imanah, 2017) menyimpulkan reorder dipenagruhi oleh brand image. 


\section{Hasil Hipotesis 2}

Diketahui usability aplikasi mempunyai $\mathrm{t}$ hitung 2,639 dan $\mathrm{t}$ tabel 1,984 maka $(2,639>1,984)$ serta signifikansi 0,010<0,05. Disimpulkan bahwa reorder customer Grab di Kota Solo dipengaruhi oleh usability aplikasi. Sependapat penelitian (Basyar dan Sanaji, 2016) Mengungkapkan reorder dipengaruhi oleh usability aplikasi.

\section{Hasil Hipotesis 3}

Diketahui promosi mempunyai t hitung -145 dan t tabel 1,984 maka $(145<1,984)$ serta signifikansi 0,885>0,05. Disimpulkan reorder customer Grab di Kota Solo tidak dipengaruhi promosi. Tidak selaras dengan penelitan (Muiz, Rachma dan Slamet, 2015) mengungkapkan reorder diengaruhi promosi.

\section{KESIMPULAN}

Tujuan penelitan ini yaitu untuk mengetahui dampak brand image, usability aplikasi dan juga promosi terhadap reorder customer Grab di Kota Solo. Dengan total 100 responden, menggunakan uji regresi linier berganda. Dari uji data tersebut secara parsial diperoleh reorder customer Grab di Kota Solo dipengaruhi oleh brand image. Variabel reorder customer Grab di Kota Solo dipengaruhi oleh usability aplikasi. Promosi tidak berpengaruh terhadap reorder customer Grab di Kota Solo. Sedangkan secata bersamaan brand image, usability aplikasi dan promosi berpengaruh terhadap reorder customer Grab di Kota Solo. Reorder customer Grab di Kota Solo dijelaskan brand image, usability aplikasi dan promosi $48 \%$ dan sisanya $52 \%$ tidak dijelaskan di penelitian ini.

Diharapakan penelitan selanjutnya menambah variabel penelitian dan memperpanjang perioder penelitian. Berdasrkan hasil dari penelitian ini saran bagi perusahaan adalah sebaiknya memperhatikan promosi yang dilakukan agar lebih efektif lagi berjalannya. Kemudian untuk brand image yang sudah bagus serta kemudahan aplikasi harus di pertahankan kualitasnya dan harus selalu dikembangkan kedepannya

\section{DAFTAR PUSTAKA}

Apriyani, Y. (2018). Pengaruh Brand Image, Harga dan Kualitas Pelayanan Terhadap Keputusan Pembelian Ulang Pizza Hut Di Kota Padang. 1-10.

Basyar, K., \& Sanaji. (2016). Pengaruh Persepsi Kemudahan Dan Perpepsi Manfaat Terhadap Niat Beli Ulang Secara Online Dengan Kepuasan Sebagai Variabel Intervening. BISMA, 204-217.

Efendi, Z., Widyaningrum, M. E., \& Imamah, N. (2017). Pengaruh Promosi, Citra Merek, dan Kepuasan Konsumen Terhadap Pembelian Berulang Produk Elzatta di Surabaya. Jurnal Manajemen Branchmark, 1097-1109.

Ghozali, I. (2015). Aplikasi Analisis Multivariate dengan Program SPSS. Semarang: Badan Penerbit Universitas Diponegoro. 
Muiz, M., Rachma, N., \& Slamet, A. R. (2019). Pengaruh Sales Promotion dan Kualitas Pelayanan Terhadap Minat Pembelian Ulang di Mediasi Variabel Kepuasan Konsumen. E-Jurnal Riset Manajemen, 50-62.

Muliati, Y. E., \& Widiastuti. (2014). Pengembangan Model Pembelian Berulang Pada Pusat Grosir Dengan Antisiden Brand, Quality, Patron Status, Fashion Involvement dan Store Atmosphere. Jurnal NeO-Bis, 164-178.

Pradana, M. D. (2018). Pengaruh E-Service Quality Dan Kemudahan Terhadap Niat Beli Ulang Dengan Kepuasan Sebagai Variabel Intervening. Jurnal Ilmu Manajemen, 1-10.

Sugiyono. (2013). Metode Penelitian, Kuantitatif, Kualititaif, dan R\&D. Bandung: Alfabeta.

Sugiyono. (2017). Metode Penelitian, Kuantitatif, Kualitatif, dan R\&D. Bandung: Alfabeta.

Suigyono. (2015). Metode Penelitian dan Pengembangan (Research and Developent/ R\&D. Bandung: Alfabeta.

Tiefani, \& Saputra. (2020). Analisis Faktor-faktor Yang Mempengaruhi Minat Beli Ulang Konsumen Pada PT Anugerah Avava Cemerlang Batam. Jurnal EMBA, 2095-2105.

Trisnawati, E., Suroso, A., \& Kumorohadi, U. (2012). Analisis Faktor-faktor Kunci Dari Niat Pembelian kembali Secara Online (Study Kasus Pada Konsumen fresh Shop. Jurnal Bisnis Dan Ekonomi, 126-141.

Widiana, M. E. (2010). Penggunaan Teknologi Internet dalam Sistem Penjualan Online untuk Meningkatkan Kepuasan dan Pembelian Berulang Produk Batik pada Usaha Kecil dan Menengah di Jawa Timur. Jurnal Manajemen Dan Kewirausahaan, 71-81. 